\title{
LONG HOUSE MEDICINE
}

\author{
Captain N. G. FUTTER \\ M.B., B.S., R.A.M.C.
}

PART of a section of 19 Field Ambulance spent a month in the Bintulu district of Sarawak, employed exclusively in the "Hearts and Minds" campaign. Although medical aid has been a major part of this programme, this was the first time a medical unit has been fully employed in this way. The team of one medical officer, two sergeants and six men visited forty long houses and bazaars, and treated over two thousand patients.

Bintulu is at the mouth of a large, easily navigable river system, and it was by river that we travelled to the long houses. Apart from rubber plantations and timber camps, the whole area is dense jungle and mangrove swamps, with very few inhabitants. The majority of the people in the district are Ibans, with a few Chinese and Malays in the bazaars.

\section{Iban Way of Life}

The Ibans' home, the long house (Fig. 1), can be described as a horizontal block of

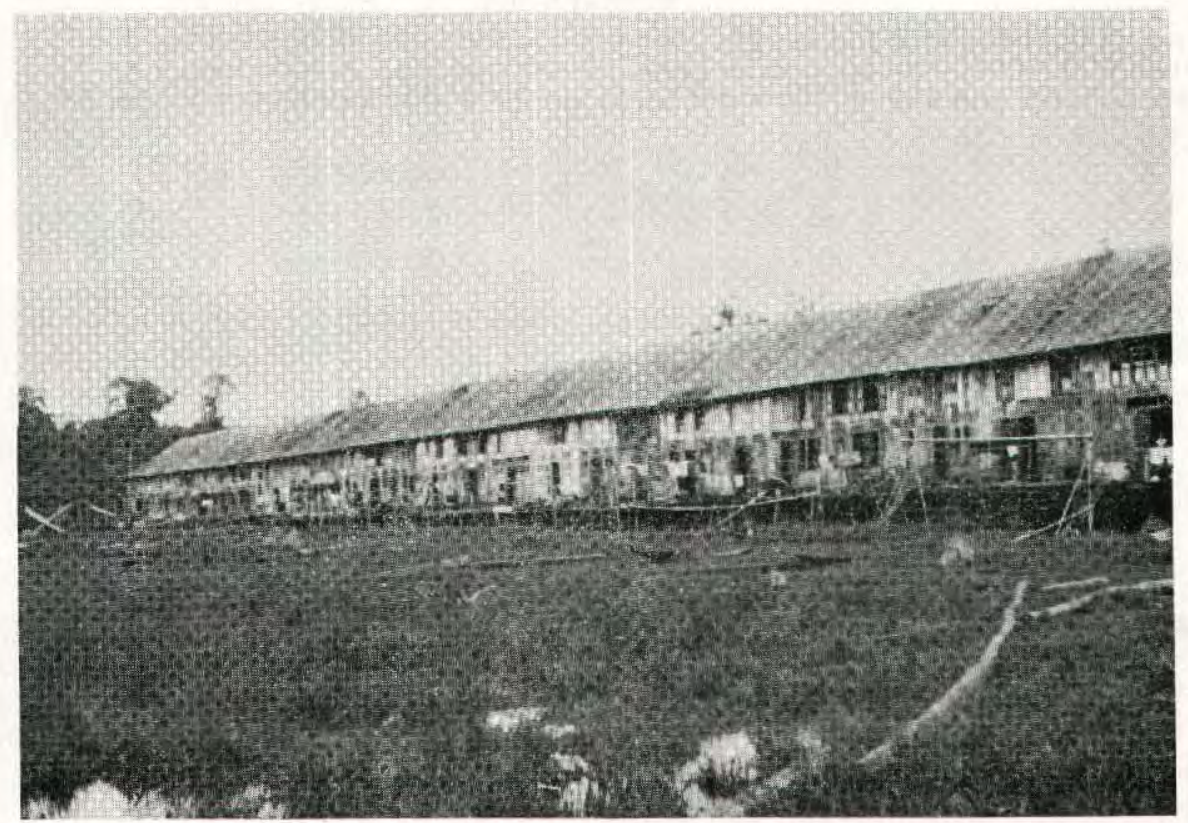

Fig. 1-Iban long house built entirely of wood.

flats, with doors leading off a long verandah. The number of doors varies, but it is usually between fifteen and thirty. Each door leads to a family's part of the house; two rooms, 
one for cooking, the other for living, eating and sleeping in. The houses, built entirely of wood, are on stilts, and underneath live pigs and chickens and any other animals they might have. All waste, human and otherwise goes into the river or more usually through the floor to the animals beneath. A perfect cycle for certain helminthic diseases is thus established.

Ibans' staple diet is rice, which they grow in paddy fields hacked from the neighbouring jungle. To this is added bananas, fish, and occasionally chicken and pork. The animals are bred for their monetary rather than their food value. Water is collected from the river by the women; in some cases it is boiled, but generally not. In many ways the Ibans are still a very primitive race; one often sees a bag of skulls hanging from the roof, a relic of their not too distant head-hunting days. In one long house the skulls were hanging over a paraffin refrigerator, while on the shelf a transistor radio blared forth the latest Beatles' record.

Iban courtship and marriage is a very simple affair. A young man visits a girl in her bed when everyone else in the room is sleeping, and after seven consecutive nights they are pronounced married. If his intentions are not honourable, the chief will tell him to stop calling after the third night. Once married, a bad dream or one of several bad omens happening to either partner is enough for divorce. When a child is born the mother is sat up against a wooden board with her back to a fire. The fire is kept burning for up to three weeks, and there the mother must sit day and night. The Ibans claim this drains the blood but it frequently results in burns.

Many long houses have a witch doctor. We were fortunate in seeing one at work one evening on a boy with a fever. The patient lay on the floor, his head painted with coloured dyes, while the old man flashed beads and his parang over his head. At our sick parade the next morning, we not only attended the boy, but also the witch doctor who had arthritis.

\section{Available Medical Facilities}

Most of the easily accessible long houses are visited by a hospital assistant from Bintulu. The hospital assistant, who had had three years training, travels in a boat equipped as a dispensary. In Bintulu there is a dispensary run by another hospital assistant and here there are in-patient as well as out-patient facilities. Anyone requiring surgery, $\mathrm{x}$-ray or laboratory investigation has to go 100 miles to a hospital, where there is a doctor. This is a 12 hour sea voyage or in emergencies, 40 minutes by air.

\section{Clinics in Long Houses}

On arrival at a long house we were greeted by the head man, and taken to the verandah outside his door. Here we sat on the floor while everyone gathered around, and the young men fetched our kit. Those sick were pushed forward for treatment while several people shouted out their symptoms. A smattering of Iban is soon learned, and before long, a reasonable medical vocabulary obtained. Examination under these circumstances is obviously limited but so long as everyone went away having been examined, and got some pills, or better still an injection they were happy. At the end of every clinic, there were several old women and young men who complained of headache, fever, cough, abdominal pain and generalised weakness, that they were sure would be cured by some medicine. An injection of vitamin complex usually brought about instant relief. 


\section{Diseases Encountered}

Malaria. Sarawak has had a malaria eradication programme in operation for several years. A blood film was taken from anyone who had the slightest suspicion of malaria, and this was sent to the central control laboratory for examination. Duplicate films were made and these examined on the spot with a portable microscope; three positive cases were found. The eradication team visits all long houses where there are cases and takes blood films from everyone. They stay in the house for several days, treating all cases and spraying the house and likely breeding areas.

Helminths. "All the adults have hookworm, and all the children round worm ", the hospital assistant claimed. Epigastric pain and anaemia are very common in adults, and the pain seems to be relieved by a single dose of Alcopar in the majority of cases. Children with protuberant abdomens are also common, almost universal in some long houses. In one long house all the children were given a dose of piperazine. All except two passed round worms, one child passed thirty eight. The method of waste disposal, through the floor is obviously largely responsible for this mass infection. Treatment only produces a temporary freedom from infestation.

El Tor cholera occurred in 1964, killing five people. It began in a particularly filthy long house, and spread to neighbouring ones. Despite vigorous propaganda, the people there are still not boiling any drinking water.

Amoebic dysentery was diagnosed in several cases on clinical grounds and it was treated

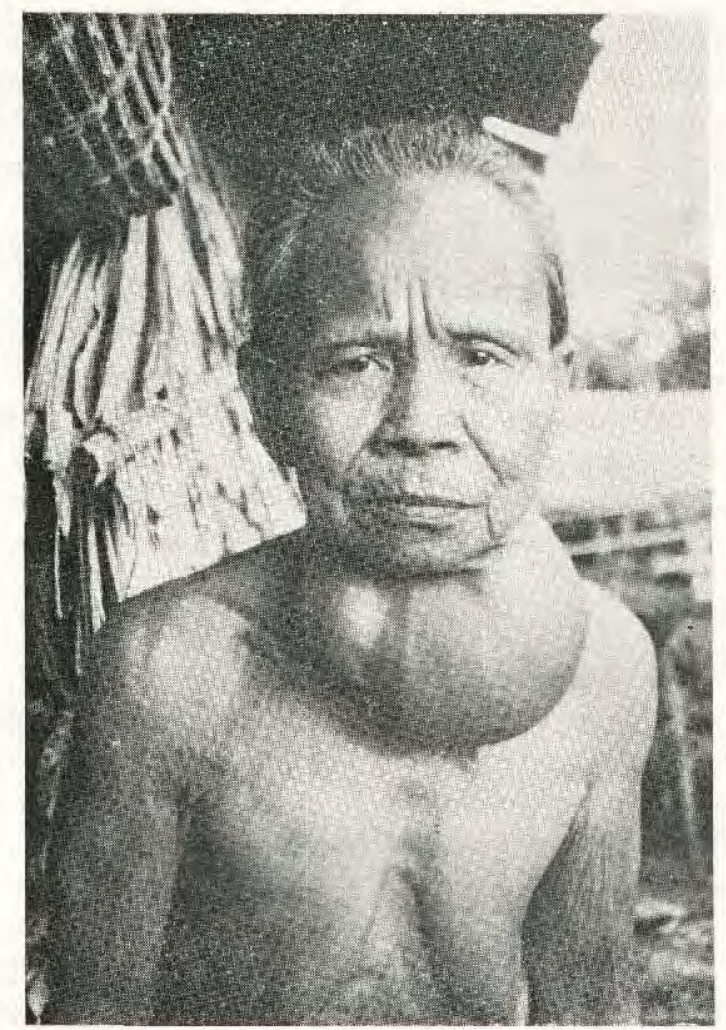

Fig. 2-Goitre in Iban woman; goitres of this size are not uncommon. 
with a week's course of Furamide, usually preceded by a dose of Alcopar. This is unsatisfactory, but it was impossible to examine the stools on every case of diarrhoea.

Pulmonary disease. Pulmonary tuberculosis occurs in practially every long house. All suspected cases are sent to hospital for $\mathrm{x}$-ray and sputum examination. If these are positive treatment is started in hospital, and continued at home under the hospital assistant, with regular check ups at the hospital. B.C.G. vaccination is being given in some of the larger towns in Sarawak. A tuberculosis eradication programme is urgently needed in the country, but at present it is not possible for financial reasons.

Goitre. In many long houses every woman and many men have goitres, often of enormous dimensions (Fig. 2). The more children a woman has, the larger the goitre seems to become. The addition of iodine to salt is being introduced into Sarawak, and this should do much to prevent this major cause of complaint in the future.

Tumour. This tumour (Fig. 3) had been slowly growing for 15 years. The woman came

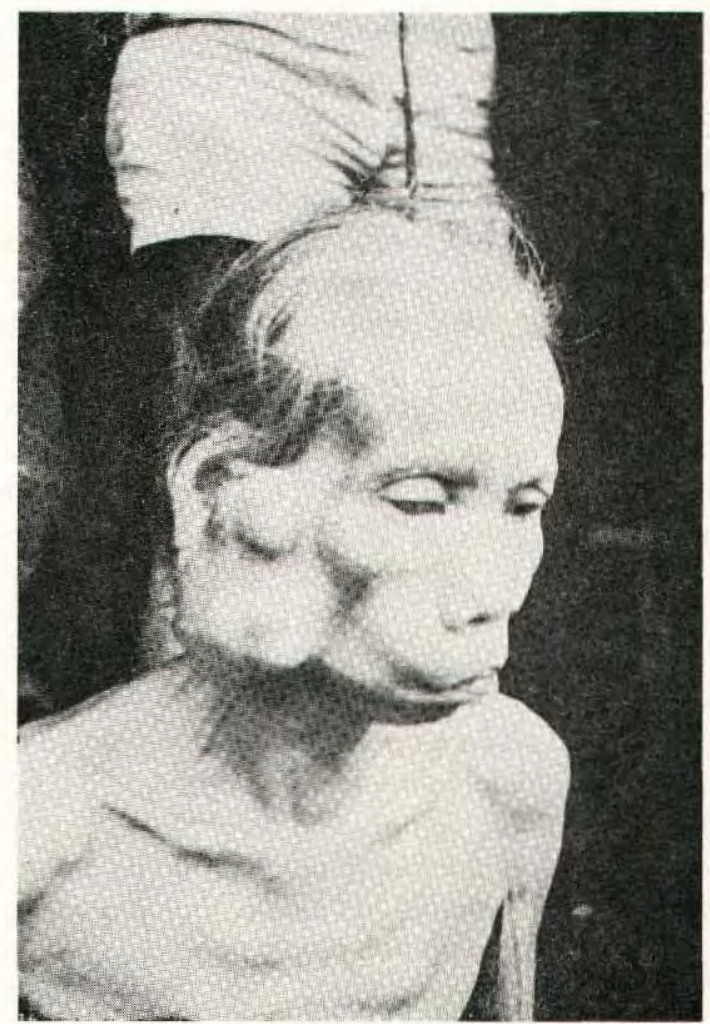

Fig. 3-Tumour in Iban woman.

from an isolated village where there was no word for a doctor in the local language. The tumour was bony hard and seemed to have originated in the parotid. There was facial palsy and the right eye had been destroyed. She refused to go to hospital.

Skin diseases. These are very common, especially in children. Infected bites and abrasions often develop into enormous abscesses and ulcers, some of which have been present for 
over a year. These were dressed, and the patient instructed to go to the dispensary for a change of dressing. Penicillin was given by injection with an oral course to follow. In one district there was an epidemic of chicken pox, and most of the children had secondary infection. Infants being breast fed were much less severely affected than those on an adult diet. I took a photograph of two severely affected children, and the mothers of all the others brought their children forward for the therapeutic photograph.

Ophthalmic disorders: Trachoma was seen in approximately ten per cent of all adults examined. Most were in stages 3 and 4 of the MacCullen classification, and were thus beyond the point of no return as far as medical treatment was concerned. Cases which were seen in the earlier stages often were not complaining of any eye disorder. They were given a 10 day course of Albucid eye drops, and were to be followed up by the hospital assistant. Cataract for no obvious cause was common in the elderly. Ibans often complained of poor night vision, some had xerophthalmia as well. Their diet contains little vitamin A. Many of these people pluck out all their eyelashes in an attempt to improve their night vision.

Obstetrics and gynaecology. Some long houses have a midwife who has had six weeks elementary training. One I met had been introduced to catheters, but did not bother to sterilize them. Only six patients were seen, five with pyelitis of pregnancy, the sixth an attempted criminal abortion. Criminal abortion is said to be common, the instruments used being palm leaves or roots introduced into the cervix.

Anaemia is common in pregnancy; iron and vitamins were dispensed to all pregnant and lactating women. Breast feeding continues for two or three years, usually until the child is displaced by a new arrival. After six months, milk is supplemented with the adult diet.

Deficiency diseases. Very few cases of frank malnutrition were seen. Two cases of dry beri-beri were treated with $100 \mathrm{mg}$. of vitamin $B_{1}$ with apparently good results. The rice is not highly polished, being pounded by hand. Probable vitamin A deficiency of the eyes has already been described. No cases of kwashiorkor or gross protein deficiency were seen.

\section{Conclusions}

The Ibans are a delightful and friendly people, who are grateful for any medical help given. In many cases the diagnosis was made on a limited history and far from complete examination. Unfortunately we were unable to follow up any of the cases, and so any assessment of benefits and value of our visits is purely guesswork.

Much is being done to improve the health of these people, but it is severely restricted by lack of money and trained personnel. Malaria is under control; tuberculosis is obviously the next choice for eradication. One wonders to what extent civilization is affecting these people. Instead of eating their pigs and chickens, they now sell them for money to buy outboard motors and transistor radios.

Their standard of hygiene is very poor but they can see no connection between it and disease. Any change in the method of waste disposal such as a deep trench latrine would deprive the livestock of most of its food and would present fresh problems of maintenance and above all of persuading the people to use it.

The forces in Borneo are doing much to help the people, but when they withdraw there is going to be a vacuum in many of the essential services. Confrontation is taking much of the money that should have been used for improving the standards of living. 